\title{
Estimation of residual stress field uniformity when using the Ring-Core method
}

\author{
František Menda ${ }^{1, a^{*}}$, Patrik Šarga ${ }^{2, b}$ and František Trebuňa ${ }^{3, c}$ \\ 1,2,3 Technical University of Košice, Faculty of Mechanical Engineering, Department of Applied \\ Mechanics and Mechatronics; Letná 9, 04200 Košice, Slovakia; \\ afrantisek.menda@tuke.sk, ${ }^{b}$ patrik.sarga@tuke.sk, ${ }^{9}$ frantisek.trebuna@tuke.sk
}

Keywords: Ring-Core, residual stress, calibration coefficients.

\begin{abstract}
The evaluation of residual stresses using Ring-Core method requires complex analysis of the acquired strain values. The development is based on ASTM Standard E837-08 for hole-drilling method, but the specific approach for Ring-Core is needed. The input data sets obtained from strain gage rosette are categorized by proposed uniformity test. The influence of geometric parameters of the specimen on this test and subsequently on the both uniform and nonuniform calculations is considered.
\end{abstract}

\section{Introduction}

The Ring-Core method is a semi-destructive method for determining residual stresses inside the material. Relieved strains are measured by the strain gage rosette attached on top of the specimen during the notch creation. Created annular groove has following parameters: $D_{1}=14 \mathrm{~mm}$-inner, $\mathrm{D}_{2}=18 \mathrm{~mm}$-outer diameter and maximum milling depth $\mathrm{z}=5 \mathrm{~mm}[1,2]$. The milling procedure is divided into small step increments and the corresponding strain values are recorded at each milled step.

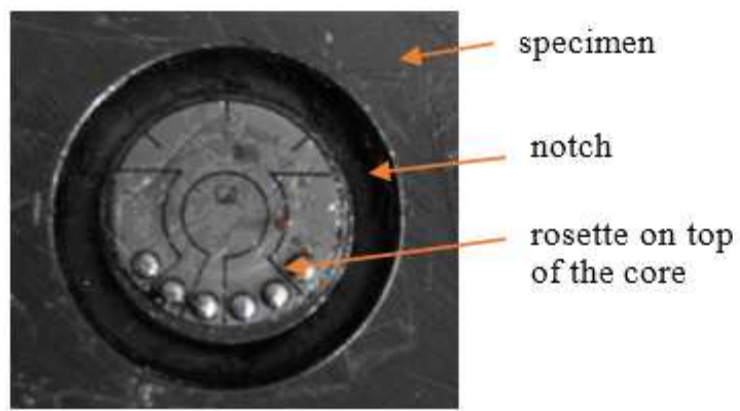

Fig. 1 Attached strain gage rosette K-RY51-5/350 at the top of the isolated core

When measuring the residual stresses of unknown principal directions, three functions of the relieved strains in the dependence on the milled depth are obtained from the strain gage rosette (e.g. K-RY51 from HBM). These three functions with material properties (Young's modulus E, Poisson's number $\mu$ ) and geometric parameters of tested specimen represent the input data for evaluation of the particular residual stress components. Evaluated residual stress can be uniaxial or biaxial, with homogenous or nonhomogeneous distribution over the milled depth.

Determination of the residual stress field uniformity in the dependence on different geometric parameters of the specimen is described in this article. The research was done by the simulation methods using finite element method (FEM). The material parameters in all proposed simulations were the same $(E=210 \mathrm{GPa}, \mu=0,3)$.

\section{Simulation model}

It is obvious from hither-to published scientific works that to evaluate magnitude, direction and sense of residual stress of any kind, it is sufficient to determine universal calibration coefficients from a simple model $[1,3,4]$. Therefore, a cube model of sufficiently large parameters was chosen to avoid the influence of the model's geometrical boundaries on the relieved strains. To save the 
calculation time, only a quarter model of cube was used (dimensions of quarter model: $50 \mathrm{~mm} \mathrm{x}$ $50 \mathrm{~mm} \times 100 \mathrm{~mm}$ ). Fig. 2 shows the simulation model with the annular notch and measuring grids of the strain gage rosette. Simulated measuring grids represent the real strain gage rosette XY51 which is sufficient for simulating the residual stresses of known principal directions. The symmetry fixtures and fixed point A withdraw all degrees of freedom.

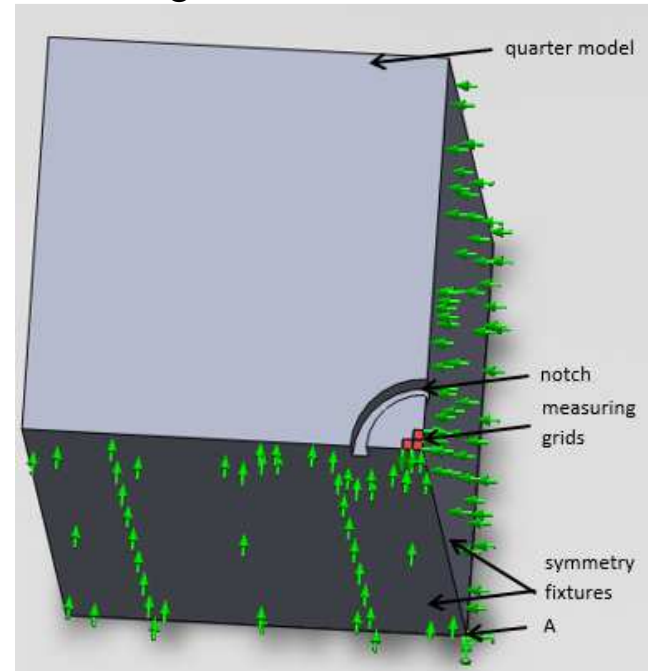

Fig. 2 Quarter simulation model

Model activation. Residual stress in simulation is represented by known stress activation with the same deformation changes of the model. There are two types of model activation: activation of outer faces of the model (Fig. 3a), suitable for quick and accurate uniform stress simulations. In case of nonuniform stress distributions, loads placed on the inner faces at each milled step of the annular groove (Fig. 3b) are more suitable.

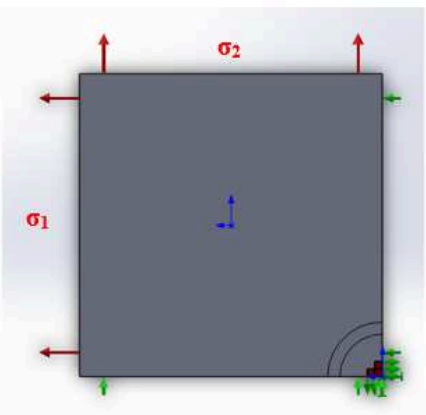

a)

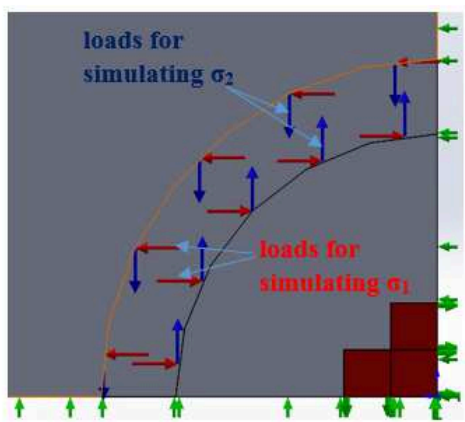

b)

Fig. 3 Two types of loading the model

\section{Uniformity test}

The standard ASTM E837-08 [5] describes the judgment of residual stress field uniformity in hole-drilling method. Similar approach is used for the Ring-Core method. The above mentioned model is loaded by a uniaxial uniform state of stress $\left(\sigma_{1}=60 \mathrm{MPa}, \sigma_{2}=0 \mathrm{MPa}\right)$, according Fig. $3 \mathrm{a}$. Subsequently three functions of relieved strains are acquired from measuring grids $\left(\varepsilon_{a}, \varepsilon_{b}, \varepsilon_{c} ; a, b, c\right.$ represent three measuring directions) and corresponding combination strains $p, q$ and are calculated using Eq. 1-3. Each set of combination strains $p$ and the larger of $q$ and $t$ are expressed as a percentage of their values at the maximum specified milled depth. Fig. 4 shows the plots of these percent strains versus scaled depth $\left(z / D_{1}\right)$.

$$
\begin{aligned}
& \mathrm{p}=\left(\varepsilon_{\mathrm{c}}+\varepsilon_{\mathrm{a}}\right) / 2 \\
& \mathrm{q}=\left(\varepsilon_{\mathrm{c}}-\varepsilon_{\mathrm{a}}\right) / 2
\end{aligned}
$$


$\mathrm{t}=\left(\varepsilon_{\mathrm{c}}+\varepsilon_{\mathrm{a}}-2 \varepsilon_{\mathrm{b}}\right) / 2$
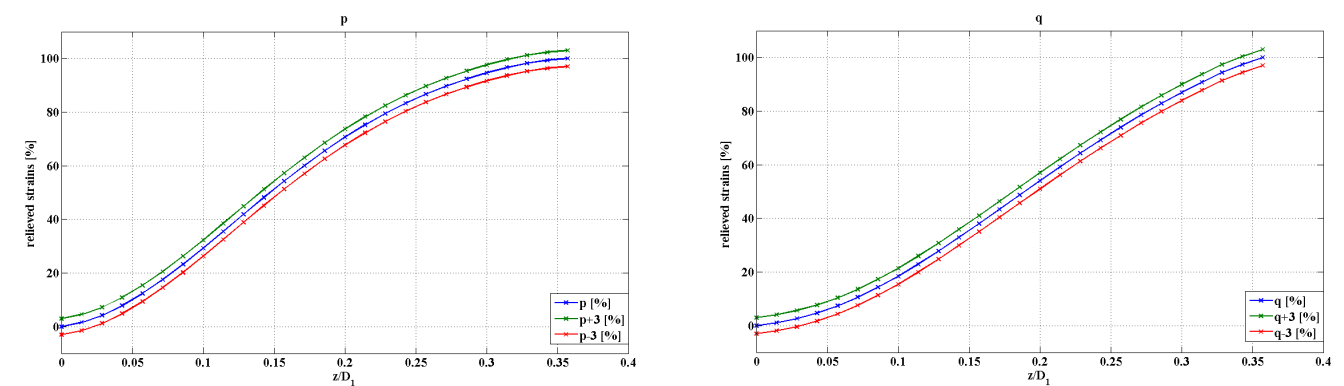

Fig. 4 Graphical limits of the function $p$ and $q$

If the waveforms of functions $p, q(t)$ of any kind of residual stress field are between the graphical limits shown in Fig. $4( \pm 3 \%)$ then the stress field passes the uniformity test. It means that particular residual stress components are uniform over the milled depth. Simulations of different model's geometric characteristics has shown the minimal model dimensions are $20 \mathrm{~mm} \times 30 \mathrm{~mm} \times$ $40 \mathrm{~mm}$ for using graphical limits from Fig.4. If any dimension is smaller, other limits have to be determined.

This graphical test is not a sensitive indicator of stress field uniformity. Specimens with significantly non-uniform stress fields can also yield percentage relieved strain curves substantially similar to those in Fig. 4. However it is a good indicator for using an integral evaluation method.

\section{Integral evaluation method}

Integral evaluation method assumes that residual stress at each milled depth is influenced by previous steps. Therefore this method is suitable for nonuniform residual stress field evaluation. If $i=1, . ., n$ is the step number, then three relieved strain functions apply the following:

$$
\varepsilon_{\mathrm{ki}}=\sum_{\mathrm{j}=1}^{\mathrm{i}} \varepsilon_{\mathrm{kij}},(\text { direction } \mathrm{k}=\mathrm{a}, \mathrm{b}, \mathrm{c}) \text {, }
$$

where relieved strains $\varepsilon_{k i j}$ depend on the residual stress acting in the layer $j$ at the step $i$. The principle of determinig the residual stresses components is shown in Fig. 5 [1, 5].

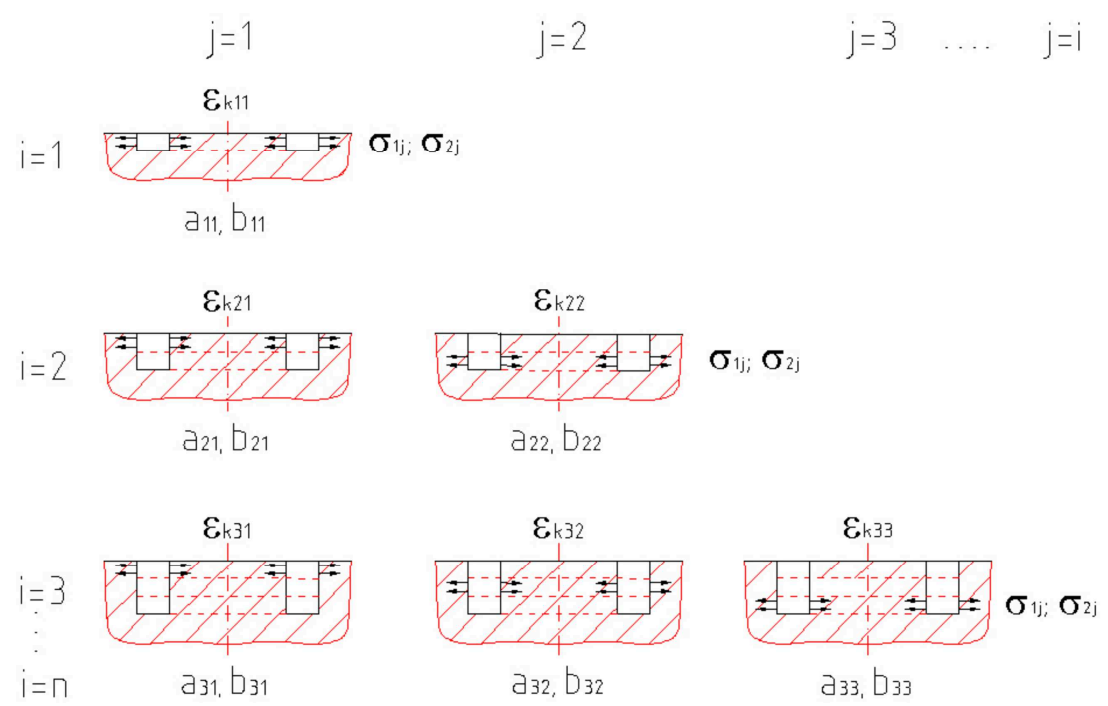

Fig. 5 The principle of the integral method [1]

Subsequently, it is possible to determine the influence coefficients $a_{i j}$, $b_{i j}$. The determination is based on the Ajovalasit's work [6] with some equations modifications. Biaxial symmetrical state of stress $\sigma_{1}=\sigma_{2}=40 . z+100[\mathrm{MPa}]$ was simulated to obtain the matrix a. Coefficients $a_{i j}$ are determined like: 


$$
\mathrm{a}_{\mathrm{ij}}=\frac{\mathrm{E} \cdot \varepsilon_{\mathrm{aij}}}{\sigma_{\mathrm{i}}} \cdot \frac{1}{1+\mu} .
$$

To determine coefficients $b_{i j}$ the unsymmetrical state of stress $\sigma_{1}=-\sigma_{2}=40 . z+100$ [MPa] was simulated to get:

$$
\mathrm{b}_{\mathrm{ij}}=\frac{\mathrm{E}}{\sigma_{\mathrm{i}}} \cdot \varepsilon_{\mathrm{aij}} \text {. }
$$

Using Eq. 4 and subsequently Eq. $1 \div 3$ the combination of stresses represented by $P, Q$ and $T$ are calculated:

$$
\begin{aligned}
& P=\frac{E . p}{\bar{a} .(1+\mu)^{\prime}} \\
& Q=\frac{E . q}{\bar{b} .}, \\
& T=\frac{E . t}{\bar{b}} .
\end{aligned}
$$

The magnitudes of residual stress componenets are determined as follows:

$$
\sigma_{1,2}=\mathrm{P} \pm \sqrt{\mathrm{Q}^{2}+\mathrm{T}^{2}}
$$

\begin{tabular}{|c|c|c|c|c|c|c|c|c|c|}
\hline & $\mathrm{z}_{i}[\mathrm{~mm}]$ & \multicolumn{8}{|c|}{$-a_{i i}$} \\
\hline $\mathrm{i}=1$ & 0,6 & 0,0481 & & & & & & & \\
\hline$i=2$ & 1,05 & 0,0771 & 0,0382 & & & & & & \\
\hline$i=3$ & 1,45 & 0,0999 & 0,0582 & 0,0339 & & & & & \\
\hline$i=4$ & 1,85 & 0,1174 & 0,0719 & 0,0497 & 0,0316 & & & & \\
\hline $\mathrm{i}=5$ & 2,3 & 0,1322 & 0,0836 & 0,0613 & 0,0473 & 0,0322 & & & \\
\hline $\mathrm{i}=6$ & 2,8 & 0,1444 & 0,0930 & 0,0703 & 0,0575 & 0,0481 & 0,0304 & & \\
\hline $\mathrm{i}=7$ & 3,5 & 0,1541 & 0,1007 & 0,0777 & 0,0657 & 0,0593 & 0,0477 & 0,0338 & \\
\hline \multirow[t]{3}{*}{$i=8$} & 5,0 & 0,1615 & 0,1064 & 0,0829 & 0,0716 & 0,0668 & 0,0578 & 0,0545 & 0,0396 \\
\hline & & $j=1$ & $j=2$ & $j=3$ & $\mathrm{j}=4$ & $\mathrm{j}=5$ & $\mathrm{j}=6$ & $\mathrm{j}=7$ & $\mathrm{j}=8$ \\
\hline & $\mathrm{z}_{\mathrm{i}}[\mathrm{mm}]$ & \multicolumn{8}{|c|}{$-b_{i i}$} \\
\hline $\mathrm{i}=1$ & 0,6 & 0,0442 & & & & & & & \\
\hline $\mathrm{i}=2$ & 1,05 & 0,0706 & 0,0355 & & & & & & \\
\hline$i=3$ & 1,45 & 0,0983 & 0,0535 & 0,0320 & & & & & \\
\hline $\mathrm{i}=4$ & 1,85 & 0,1263 & 0,0721 & 0,0473 & 0,0310 & & & & \\
\hline$i=5$ & 2,3 & 0,1585 & 0,0925 & 0,0644 & 0,0474 & 0,0331 & & & \\
\hline $\mathrm{i}=6$ & 2,8 & 0,1929 & 0,1149 & 0,0820 & 0,0641 & 0,0512 & 0,0327 & & \\
\hline $\mathrm{i}=7$ & 3,5 & 0,2356 & 0,1425 & 0,1042 & 0,0840 & 0,0724 & 0,0544 & 0,0372 & \\
\hline$i=8$ & 5,0 & 0,2987 & 0,1833 & 0,1367 & 0,1142 & 0,1027 & 0,0858 & 0,0758 & 0,0460 \\
\hline & & $\mathrm{j}=1$ & $j=2$ & $j=3$ & $j=4$ & $j=5$ & $j=6$ & $\mathrm{j}=7$ & $\mathrm{j}=8$ \\
\hline
\end{tabular}

The adequate influence coefficients were determined for eight optimized steps, proposed by Zuccarello [7]:

Tab. 1 Influence coefficients $a_{i j}$ and $b_{i j}$

Such set of universal coefficients is, however influenced by the geometric parameters of the specimen. Therefore the influence of the specimen's thickness, width and length on the method applicability was the main part of the research. The previous research of incremental method [8] at the authors' workplace showed, the minimal specimen's dimensions are $30 \mathrm{~mm} \times 40 \mathrm{~mm} \times 50 \mathrm{~mm}$ for residual stress evaluation using universal set of calibration coefficients. Now the minimal specimen's dimensions for using the integral method are considered.

The influence of specimen's thickness. To determine how the different thickness influences the coefficients, the proposed quarter model of the cube was used with the same uniform uniaxial state of stress as for uniformity test determination. The thickness of the specimen was changing from 
$10 \mathrm{~mm}$ to $50 \mathrm{~mm}$ with the increment $10 \mathrm{~mm}$. Waveform changes resultant residual stresses for specimens with the thickness greater than $50 \mathrm{~mm}$ are already negligible. Fig. 6 shows the recalculated residual stresses in the dependence on the milled depth $z$ according to Tab.1 and Eq.10.

From the results it is obvious that the minimal specimen's thickness for using universal set of influence coefficients by integral evaluation method is $30 \mathrm{~mm}$.
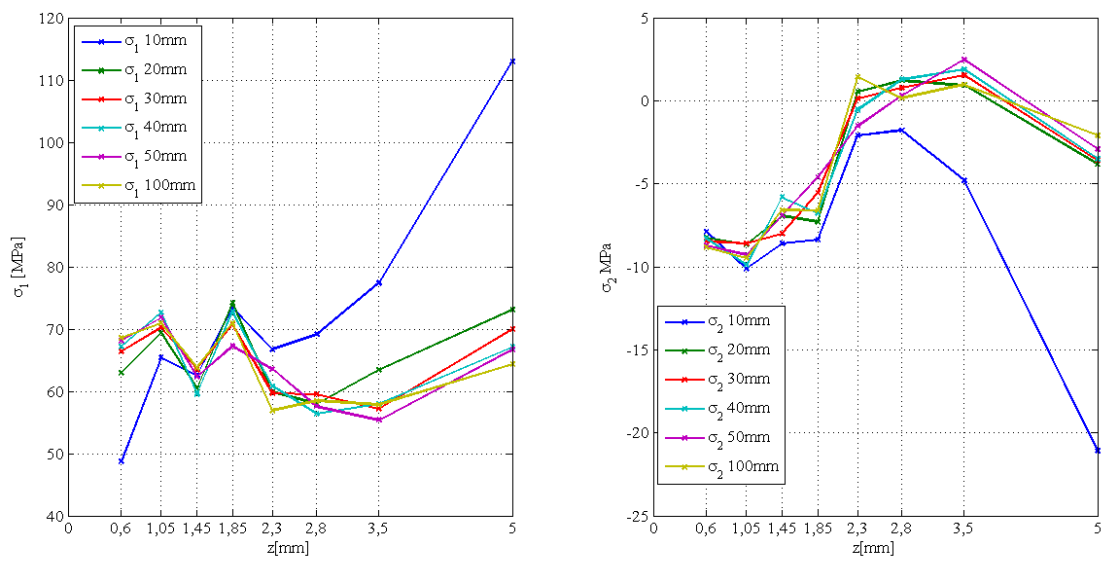

Fig. 6 Recalculated residual stresses $\sigma_{1}$ and $\sigma_{2}$ for different thicknesses

The influence of specimen's width. Similarly, the minimal specimen's width for using universal set of influence coefficients was determined. According to Fig. 7, it is $50 \mathrm{~mm}$.
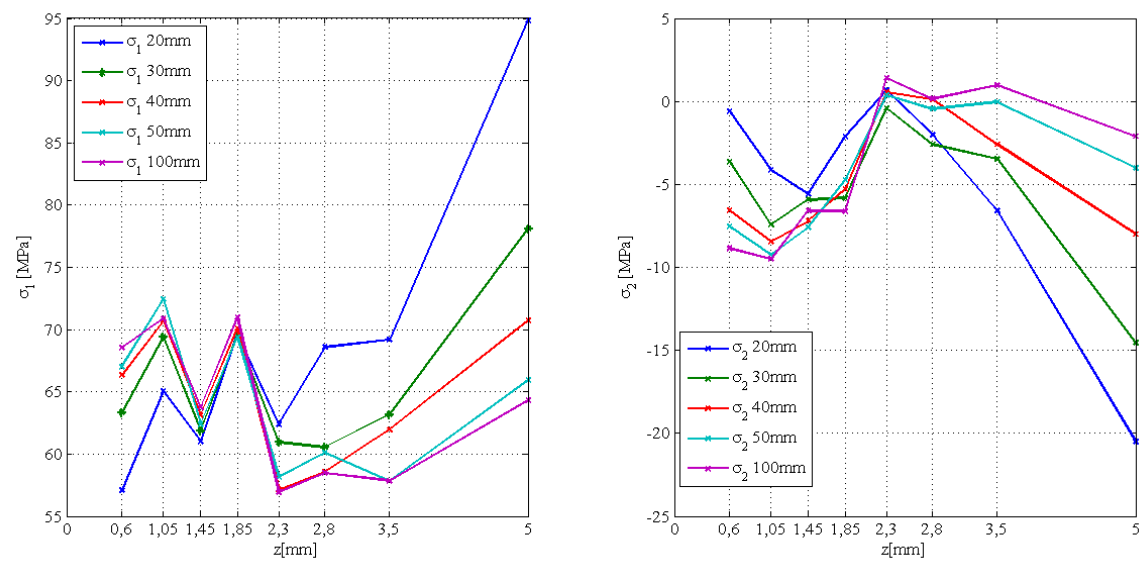

Fig. 7 Recalculated residual stresses $\sigma_{1}$ and $\sigma_{2}$ for different widths

The influence of specimen's length. By comparing the recalculated values of the resulting residual stresses for different specimen' lengths, the minimum length was set to $50 \mathrm{~mm}$.
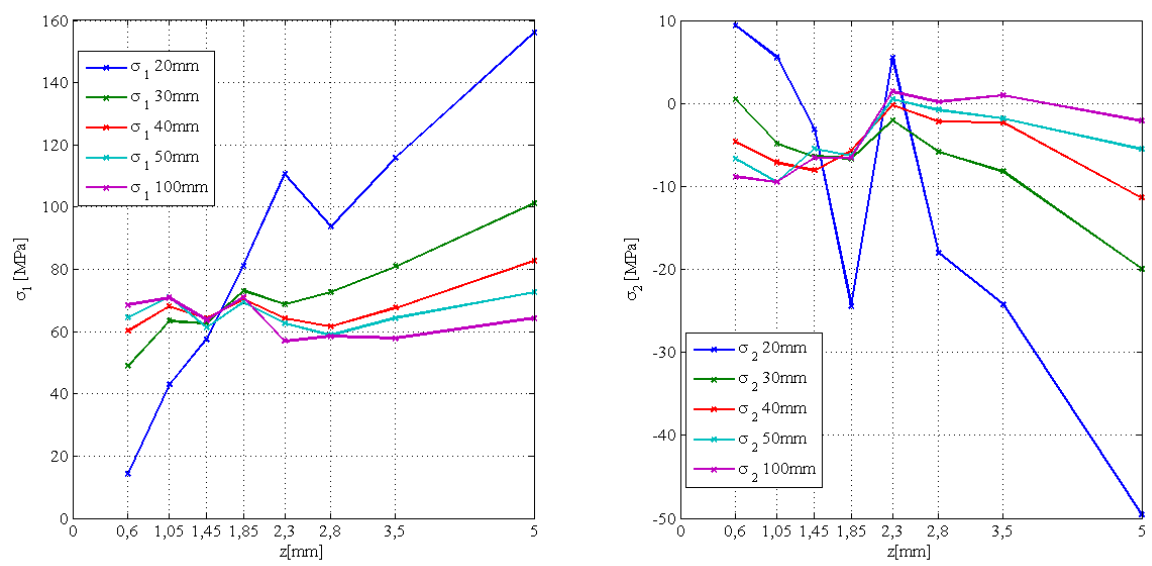

Fig. 8 Calculated residual stresses $\sigma_{1}$ and $\sigma_{2}$ for different lengths 


\section{Summary}

The residual stress evaluation by the Ring-Core method requires detailed analysis of all input parameters. Acquired functions of relieved strains in the dependence on the milled depth, material properties and geometric characteristics of the tested specimen subsequently determine the adequate calculation method. The judgment of residual stress field uniformity was proposed and the influence of specimen's thickness, width and length was considered. To be able to use universal uniformity test, the tested specimen has to be greater than $20 \mathrm{~mm} \times 30 \mathrm{~mm} \times 40 \mathrm{~mm}$. If the input data doesn't pass the uniformity test, it is recommended to use the integral calculation method. New universal influence coefficients were calculated. The determination of these coefficients includes also the influence of material properties. The influence of the specimen' dimensions was researched. If the thickness is greater than $30 \mathrm{~mm}$, width and length are greater than $50 \mathrm{~mm}$, it is possible to use universal influence coefficients for determining residual stress though only under given conditions. Otherwise, it is necessary to determine new set of coefficients. Considering the previous results for incremental method, it is obvious that choosing the adequate coefficients according to the geometric characteristics of the tested specimen have a great influence on the accuracy of the evaluated residual stresses. The research of the Ring-Core method continues with the focus on increasing the accuracy of nonuniform residual stress evaluations.

\section{Acknowledgments}

The authors would like to thank to Slovak Grant Agency - project VEGA 1/0937/12 "Development of unconventional experimental methods for mechanic and mechatronic systems" and project FGV/2013/9 "Complex analysis of the Ring-Core method in order to create the evaluation program".

\section{References}

[1] A. Civín: Komplexní teoretická analýza metody sloupku pro zjišt'ování zbytkových napětí. Brno: Vysoké učení technické v Brně, Fakulta strojního inženýrství, 2012. 130 p.

[2] E. Valentini, A. Benincasa, L. Bertelli: An automatic system for measuring residual stresses by Ring-core method. Italian Stress Analysis Association, 40th National convention, University of Palermo, 2011.

[3] S. Keil: On-line evaluation of measurement results during the determination of residual stress using strain gages. RAM, 1995, Vol.9, no. 12, p. 15-20.

[4] S. Keil: Experimental Determination of Residual Stresses With the Ring-Core Method and an On-Line Measuring System, Experimental Techniques, 1992, 16(5), p. 17-24.

[5] ASTM International Designation E 837-08: Standard Test Method for Determining Residual Stresses by the Hole-Drilling Strain Gauge Method, United States, 2008, 17 p.

[6] A. Ajovalasit, G. Petrucci, B. Zuccarello: Determination of Nonuniform Residual Stresses Using the Ring-Core Method. Transactions of the ASME - Journal of Engineering Materials and Technology, April 1996, Vol. 118, no. 2, p. 224-228.

[7] B. Zuccarello: Optimization of Depth Increment Distribution in the Ring-Core Method. Journal of Strain Analysis for Engineering Design. July 1996, Vol. 31, no. 4, p. 251-258.

[8] F. Menda, F. Trebuňa, P. Šarga: Determination of the Necessary Geometric Parameters of the Specimen in Ring-Core Method. Applied Mechanics and Materials, 2014, 486, p. 90. ISSN: $1662-7482$. 